\title{
Bioinspired Total Synthesis of ( \pm )-Antroalbocin A enabled by a Photochemical 1,3-Acyl Shift
}

\author{
Björn Siekmeyer, ${ }^{[a]}$ Dennis Lübken, ${ }^{[a]}$ Kevin Bajerke ${ }^{[a]}$ and Markus Kalesse ${ }^{*[a, ~ b, ~ c] ~}$
}

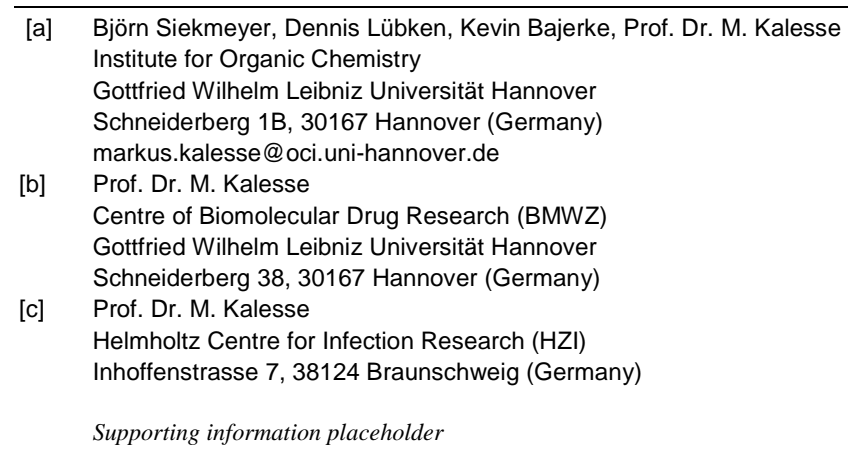

\begin{abstract}
The first bioinspired and protecting group free total synthesis of the antibacterial sesquiterpenoid antroalbocin $A$ has been achieved in five linear steps from a literature-known intermediate with an overall yield of $6.7 \%$. An intramolecular Robinson annulation gave rapid access to the tricyclic enone as starting material for a photochemical domino process of deconjugation and sigmatropic 1,3-acyl shift. Herein we further describe studies towards the use of photolytic sigmatropic 1,3-acyl shifts in the synthesis of bridged terpenoid building blocks.
\end{abstract}

Antroalbocin A (1), isolated in 2018 from the higher fungus Antrodiella albocinnamomea by Liu and co-workers, is a new antibacterial sesquiterpenoid. ${ }^{[1]}$ Its unique structure shows a novel bridged $5 / 5 / 6$ tricyclic system with three all carbon quaternary centers. Two of them are located in both bridgehead positions.

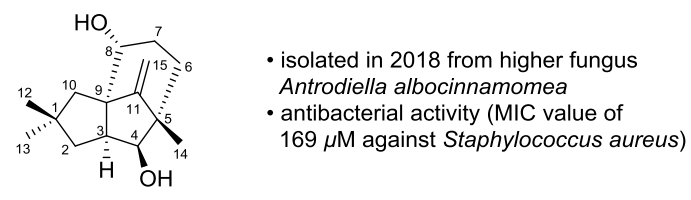

antroalbocin $\mathrm{A}(\mathbf{1})$

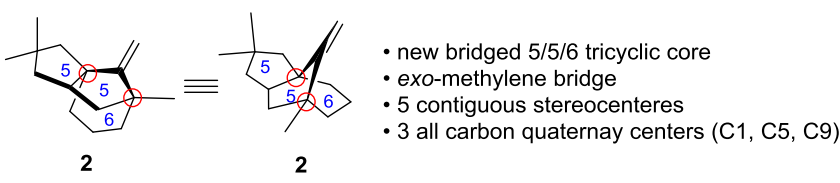

Figure 1. Antroalbocin A (1) and its carbon skeleton 2.

The 1,3-acyl shift equilibrium of bicyclic $\beta, \gamma$-unsaturated ketones 3 and $\mathbf{4}$ in excited state has been extensively studied by Paquette and co-workers (Scheme 1a). ${ }^{[2]}$ Also in 1969, Furutashi und Nakanishi observed a mutual exchange of $\mathrm{C} 4$ and $\mathrm{C} 6$ carbons in $3 \beta$-acetoxycholest-5-en-7-one (5) under photoirradiation for 12 hours. ${ }^{[3]}$ The observed skeletal rearrangement to 7 is rationalized by a photo deconjugation followed by a photolytic sigmatropic 1,3-acyl shift of C7 ketone in singlet state (Scheme 1b). ${ }^{[3]}$ a) Paquette 1969: investigations towards the photochemical 1,3-acyl shift equilibrium
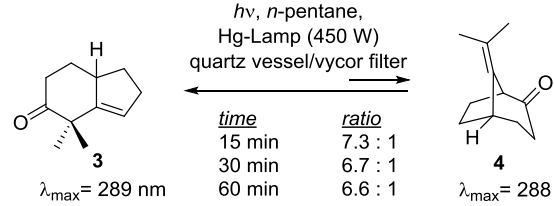

$\lambda_{\max }=288 \mathrm{~nm}$

+ further examples

b) Furutachi \& Nakanishi 1969: Photoirradiation of steroid and a mutual exchange of C4 and C6

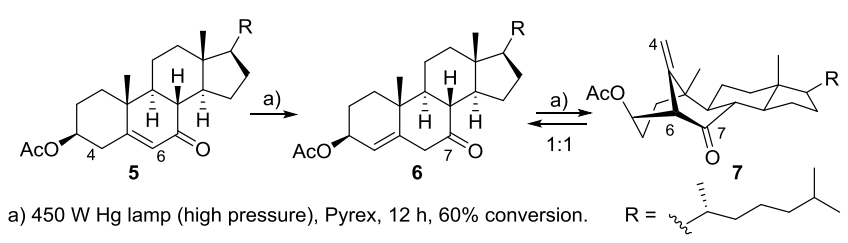

a) $450 \mathrm{~W}$ Hg lamp (high pressure), Pyrex, $12 \mathrm{~h}, 60 \%$ conversion.

c) This work: retrosynthesis of antroalbocin A (1)
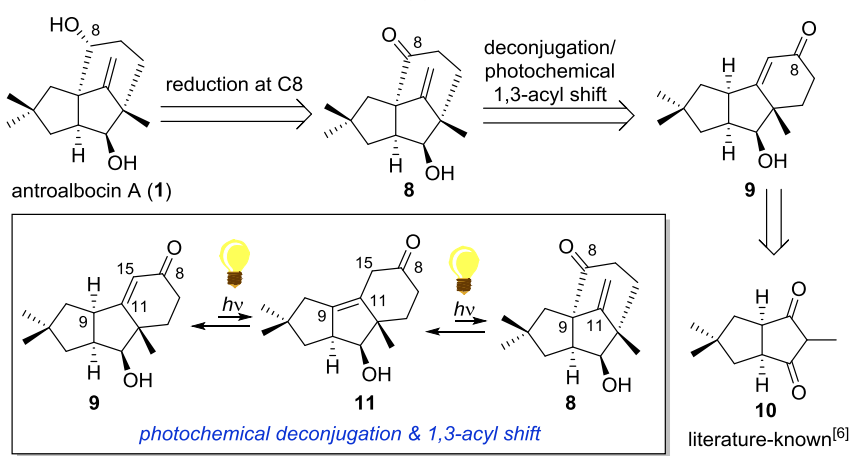

d) This work: examples of photochemical 1,3-acyl shifts from bicyclic ketones
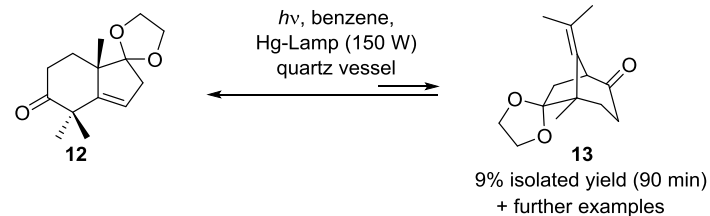

Scheme 1. a) 1,3-acyl shift equilibrium by Paquette ${ }^{[2]} 1969$; b) mutual exchange of $\mathrm{C} 4$ and $\mathrm{C} 6$ in $3 \beta$-acetoxycholest-5-en-7-one by Furutachi and Nakanishi[ ${ }^{[3]}$ in 1969 ; c) retrosynthetic analysis of 1 from 10 in this work; d) further examples of 1,3-acyl shift products. 
Our retrosynthetic strategy focusses on a photochemical 1,3-acyl shift ${ }^{[4]}$ which effects $\mathrm{C} 8$ acyl migration from $\mathrm{C} 15$ to $\mathrm{C} 9$ to generate an all carbon quaternary center at $\mathrm{C} 9$ and the exo-methylene bridge in 8 . Consequently, only a diastereoselective reduction of the C8 keto carbonyl group remains necessary to complete the synthesis of $( \pm)-\mathbf{1}$. Regarding the photochemical 1,3-acyl shift, ${ }^{[5]} \beta, \gamma$-unsaturated ketone 11 is required. Chemical deconjugation or a domino sequence of deconjugation and 1,3-acyl shift in photo-excited singlet state could be performed starting from enone $\mathbf{9}$. Our synthesis of enone 9 could be envisioned starting from literature-known symmetric 1,3-diketone $10^{[6]}$ in a sequence of annulation and carbonyl reduction (Scheme 1c).

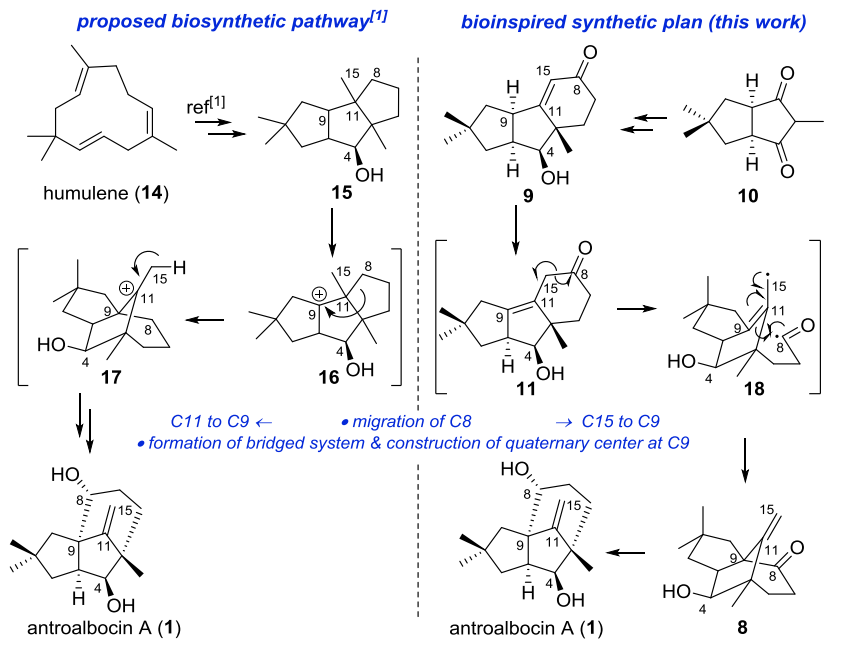

Scheme 2. Comparison of proposed biosynthetic pathway by Liu and co-workers ${ }^{[1]}$ and bioinspired synthesis (this work).

Considering Liu's proposed biosynthetic pathway, our synthesis plan is related to the suggested C8 alkyl migration in triquinane cation $\mathbf{1 6}$ from $\mathrm{C} 11$ to $\mathrm{C} 9$ (Scheme 2). ${ }^{[1]}$ This key-step is supposed to generate the bridged 5/5/6 tricyclic system with the C9 quaternary center in a bridgehead position..$^{[1]}$ Starting from 9, deconjugation to $\mathbf{1 1}$ was planned to precede the envisioned sigmatropic 1,3-shift of the C8 acyl group from $\mathrm{C} 15$ to $\mathrm{C} 9$ to mimic the putative biosynthetic route in a non-cationic fashion.

Symmetric 1,3-diketone $\mathbf{1 0}$ was synthesized from dimedone (19) in a sequence of seven literature-known steps (for detailed synthesis see supporting information). ${ }^{[6]}$ Triketone 20 was obtained in a 1,4 addition of $\mathbf{1 0}$ to methyl vinyl ketone in the presence of triethylamine with $96 \%$ yield after four days as single diastereoisomer. Primarily, the intramolecular aldol condensation for the generation of $\mathbf{2 1}$ was attempted under non-stereoselective conditions to reach rapid access to 1,3-acyl shift precursor 9. ${ }^{[7]}$ The use of common acids and bases led to decomposition of the starting material. Nevertheless, formation of 21 was obtained after ultrasonification with L-phenylalanine and pyridinium $p$-toluenesulfonate for seven days. ${ }^{[8]}$ A following diastereoselective carbonyl reduction using sodium borohydride afforded alcohol 9 in $87 \%$ yield as a single diastereomer. a)<smiles>CC(C)=O</smiles>

$80 € / 100 \mathrm{~g}$ at abcr

10

20

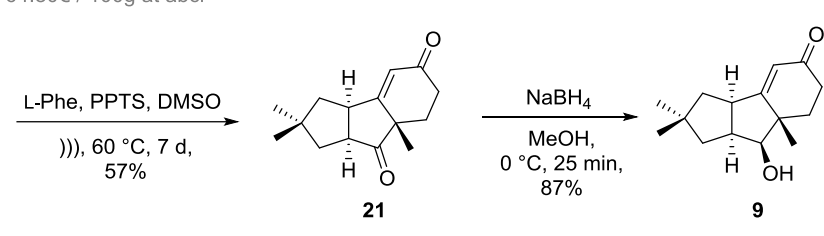

b)
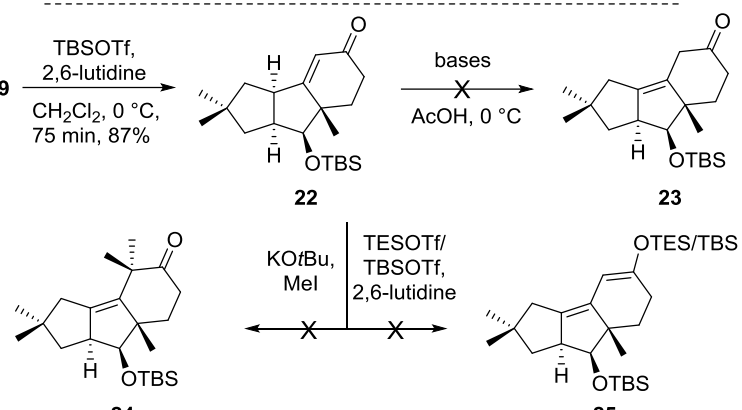

22

23

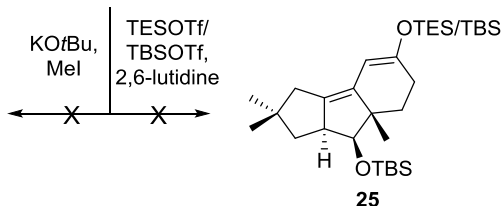

25

Scheme 3. a) Synthesis of enone 9; detailed synthesis of $\mathbf{1 0}$ see supporting information; b) deconjugation attempts of 22; for detailed conditions see supporting information, Table 2-5. MVK = methyl vinyl ketone, Phe $=$ phenylalanine, $\mathrm{PPTS}=$ pyridinium- $p$-toluene sulfonate, DMSO $=$ dimethylsulfoxide.

Attempts towards chemical deconjugation of enone 22 to the $\beta, \gamma$-unsaturated ketone were unsuccessful (see Scheme $3 b) .{ }^{[9]}$ To our delight, direct irradiation of $\mathbf{9}$ with a medium pressure mercury lamp afforded ketone $\mathbf{8}$ in a single step. Our working hypothesis is that a light-induced deconjugation ${ }^{[10]}$ of the $\alpha, \beta$-unsaturated ketone and following photochemical sigmatropic 1,3-acyl shift occurred in a domino sequence. According to rather long reaction times of photochemical deconjugation $(>10 \mathrm{~h}$ ) this is supposed to be the rate limiting step. ${ }^{[10]} 11$ could not isolated or detected by analytical methods due to its instability. ${ }^{[10 \mathrm{e}]}$ In course of this experiments we only used conditions which afford activation to the singlet state to envision the desired 1,3-acyl shift. ${ }^{[11]}$ To prevent the competing 1,2-acyl shift (oxa-di-m-methane rearrangement), ${ }^{[12]}$ the use of non-triplet activating solvents like $n$-pentane, methylene chloride, benzene or tert-butanol was a requisite. ${ }^{[1]]}$ In our experiments, using methylene chloride, benzene and tert-butanol, we never observed a 1,2-acyl shift. ${ }^{[1]}$ Optimizations of the photochemical domino cascade are shown in Table 1. Irradiations of $\mathbf{9}$ in benzene or tert-butanol gave either no reaction or very slow reaction rates. Best conditions of this reaction were found using a $450 \mathrm{~W}$ medium pressure mercury lamp in $\mathrm{CH}_{2} \mathrm{Cl}_{2}$ at room temperature $\left(32^{\circ} \mathrm{C}\right)$. The highest amount of $8(29 \%)$ in the photochemical equilibrium was detected after $4 \mathrm{~h}$ of irradiation. 8 shows reverse reactivity after few minutes in the daylight, therefore rapid reduction of the C8 keto carbonyl group is essential. Different attempts (Scheme 3) for the C8 carbonyl reduction were performed and best results were obtained using $\mathrm{D} / \mathrm{BAI}-\mathrm{H}^{[13]}$ with $42 \%$ isolated yield of 1. $\mathrm{LiAlH}_{4}$ and $\mathrm{RedAI}^{\circledR}$ gave lower yields and L-selectride ${ }^{[14]}$ showed the formation of major impurities, which could not been separated from 1. Irradiation of $\mathbf{9}$ and subsequent DiBAl-H reduction of 8 in the absence of light gave 1 in 14\% o3s applied on a $150 \mathrm{mg}$ scale. 


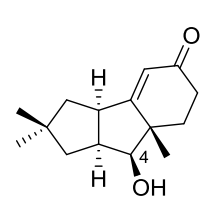

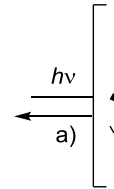

a)

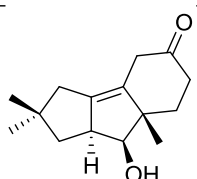

not observed

Further condition for reduction at $\mathrm{C} 8$ : i) $\mathrm{LiAlH}_{4}, \mathrm{THF},-78^{\circ} \mathrm{C}, 50 \mathrm{~min} \rightarrow 33 \%$ ii) RedAI ${ }^{\circledR}, \mathrm{THF},-78^{\circ} \mathrm{C}, 2 \mathrm{~h} \rightarrow 19 \%$ iii) L-selectride, THF, $-78^{\circ} \mathrm{C}$ to r.t., $3 \mathrm{~h} \rightarrow 50 \%{ }^{\mathrm{b})}$

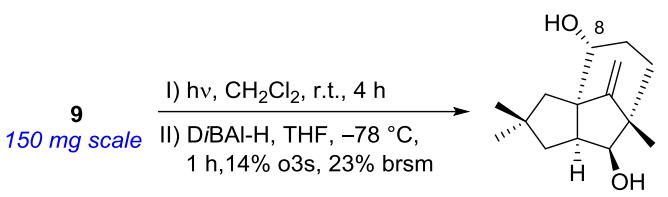

antroalbocin $\mathrm{A}(\mathbf{1})$

Scheme 4. Key step - Photochemical deconjugation of 9, 1,3-acyl shift of 11 reduction of $\mathrm{C} 8$ keto carbonyl in $\mathbf{8}$. Conditions tested for carbonyl reduction. Endgame - synthesis of 1. a) $450 \mathrm{~W}$ medium pressure mercury lamp, $\mathrm{CH}_{2} \mathrm{Cl}_{2}$, r.t. $\left(32{ }^{\circ} \mathrm{C}\right), 4 \mathrm{~h}$; b) inseparable impurities. DiBAl-H = di-iso-butylaluminum hydride.

Table 1. Optimization of deconjugation 1,3-acyl shift domino reaction (Scheme 4). For more detailed information see supporting information, Table 1.

\begin{tabular}{|c|c|c|c|c|c|c|}
\hline $\begin{array}{l}\text { solvent } \\
\text { temp. } \\
\text { Hg-lamp }\end{array}$ & & $\begin{array}{l}\mathrm{PhH}, \\
0^{\circ} \mathrm{C}, \\
200 \mathrm{~W}\end{array}$ & $\begin{array}{l}\mathrm{CH}_{2} \mathrm{Cl}_{2}, \\
0^{\circ} \mathrm{C}, \\
200 \mathrm{~W}\end{array}$ & $\begin{array}{l}\mathrm{CH}_{2} \mathrm{Cl}_{2}, \\
-78{ }^{\circ} \mathrm{C}, \\
450 \mathrm{~W}\end{array}$ & $\begin{array}{l}\mathrm{CH}_{2} \mathrm{Cl}_{2}, \\
0^{\circ} \mathrm{C}, \\
450 \mathrm{~W}\end{array}$ & $\begin{array}{l}\mathrm{CH}_{2} \mathrm{Cl}_{2}, \\
32{ }^{\circ} \mathrm{C}, \\
450 \mathrm{~W}\end{array}$ \\
\hline entry & $t / \mathrm{h}$ & \multicolumn{5}{|c|}{ Ratio $^{[a]}$ of 8 in equilibrium of 9 and 8 in \% } \\
\hline I & 1 & 0.5 & 2.5 & $0.4^{[\mathrm{d}]}$ & 12.1 & 14.0 \\
\hline II & 2 & 1.2 & 4.0 & $2.2^{[\mathrm{d}]}$ & 19.9 & 23.6 \\
\hline III & 3 & 1.9 & 6.7 & $4.1^{[\mathrm{d}]}$ & 21.6 & 27.0 \\
\hline IV & 4 & 2.6 & $15.9^{[c]}$ & $4.9^{[\mathrm{d}]}$ & 17.1 & 28.6 \\
\hline V & 5 & $3.2^{[b]}$ & $18.9^{[c]}$ & $6.8^{[\mathrm{d}]}$ & 10.4 & 26.5 \\
\hline
\end{tabular}

[a] Ratios of 8 and 9 were determined by ${ }^{1} \mathrm{H}$ NMR by comparison of the relative integrals at $\mathrm{C} 4$; [b] increasing photo decomposition; [c] $4^{\text {th }}$ to $5^{\text {th }}$ hour were measured in separate experiments; [d] formation of by-products. ${ }^{[10 c, 11]}$.

Further investigations of 1,3-acyl shifts for the construction of bridged bicyclic systems are shown in Table 2. $\beta, \gamma$-Unsaturated ketones 26, ${ }^{[15]}$ $28,{ }^{[16]} \mathbf{1 2},{ }^{[17]}$ and $\mathbf{3 0}$ were derived from $(S)$-Hajos-Parrish ketone ${ }^{[18]}$ and in all cases bridged products of 1,3-acyl shifts could be isolated. The reaction shows wide toleration of functional groups e.g. silylethers $\mathbf{2 8}$, ketals $\mathbf{1 2}$ or free hydroxyl groups $\mathbf{3 0}$. Substrates containing free hydroxyl groups and ketals gave the lowest amount of decomposition during the photochemical process. The clean reaction of substrates containing a free hydroxyl group, led to a protecting group free strategy for the synthesis of $\mathbf{1}$. To broaden the scope of this transformation notkatoon derivative $\mathbf{3 2}$ was further successfully rearranged with good yields based on recovered starting material.
Table 2. Synthetic examples of bridged 1,3-acyl shift products. The reactions were carried out in dry degassed benzene $(12.5 \mathrm{mM})$ at room temperature in quartz glass using a $150 \mathrm{~W}$ medium pressure mercury lamp. Irradiation was stopped after 90 minutes. See supporting information for detailed synthesis of starting materials.

$$
\begin{aligned}
& \text { Starting material } \\
& \text { (recovered amount) }
\end{aligned}
$$

Product

(isolated yield)

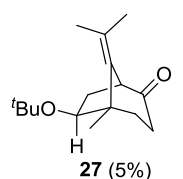<smiles>CC1(C)CCC(=O)C1(C)[18OH]</smiles><smiles>CC1=C(C)C2C(OC(C)(C)C)C(=O)CC1C2[18OH]</smiles>

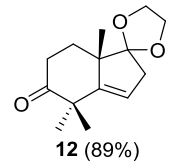<smiles>CC1=C(C)C2CC(=O)C1CC21OCCO1</smiles><smiles>CC12CCC[C@](C)(O)C1=CCC2O</smiles>

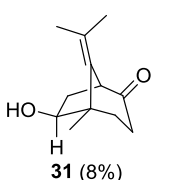<smiles>C=C(C)[C@@H]1CC=C2C(C)(C)C(=O)CC(C)[C@@]2(C)C1</smiles><smiles>C=C(C)CC12CCC(CC1=O)C(=C(C)C)C2=O</smiles>

In conclusion, we have achieved the first bioinspired and protecting group free ${ }^{[19]}$ total synthesis of the antibacterial sesquiterpenoid $( \pm)$-antroalbocin A (1) in 5 steps starting from symmetric 1,3-diketone 10 in $6.7 \%$ overall yield. The longest linear sequence includes the literature-known sequence ${ }^{[6]}$ for the synthesis of 10 from commercial dimedone (19) (7 steps, $49 \%$ o7s) and 12 steps (3.3\%) in total. The key step was performed in a photochemical domino process of deconjugation followed by 1,3-acyl shift. Furthermore, we have shown additional examples for 1,3-acyl shifts from fused $\beta, \gamma^{-}$ unsaturated ketones for the construction of their corresponding bridged bicyclic systems in terpenoid fragments.

\section{Acknowledgements}

The authors thank Dr. Thomas Huhn, Lukas Holz and Johannes Laurin Bayer for technical assistance and very helpful discussion (University of Konstanz, Germany). We are very grateful to Ji-Kai Liu, Tao Feng and Zheng-Hui Li for providing NMR data of the authentic material. Furthermore, the authors thank Dr. Linn Müggenburg, Dr. Jörg Fohrer, Monika Rettstadt und Dagmar Körtje for NMR measurements and Dr. Gerald Dräger and Anne Schulz for mass spectrometry.

Keywords: natural product synthesis • antroalbocin A • photochemistry $\bullet$ 1,3-acyl shift $\bullet$ protecting group free 
[1] W. Li, J. He, T. Feng, H.-X. Yang, H.-L. Ai, Z.-H. Li, J.-K. Lui, Org. Lett. 2018, 20, 8019-8021.

[2] L. E. Paquette, G. V. Meehan, J. Org. Chem. 1969, 34, 2, 450-454.

[3] a) N. Furutachi, Y. Nakadaira, K. Nakanishi, J. Am. Chem. Soc. 1969, 91, 4, 1028-130; b) J. Hayashi, N. Furutachi, Y. Nakadaira, K. Nakanishi, Tetrahedron Lett. 1969, 52, 4589-4591.

[4] a) G. O. Schenk, R. Steinmetz, Chem. Ber. 1963, 96, 520; b) D. I. Schuster, M. Axelrod, J. Auerbach, Tetrahedron Lett. 1963, 1911. For further examples of 1,3 acyl shifts in organic synthesis see: c) T. Bach, J. P. Hehn, Angew. Chem. Int. Ed. 2011, 50, 5, 1000-1045; Angew. Chem. 2011, 123, 5, 1032-1077; d) J. Wu, Y. Kadonaga, B. Hong, J. Wang, X. Lei, Angew. Chem. Int. Ed. 2019, 58, 32, 10879-10883; Angew. Chem. 2019, 131, 32, 10995-10999; e) B. Hong, W. Liu, J. Wang, J. Wu Y. Kadonaga, P.-J. Cai, H.-X. Lou, Z.-X. Yu, H. Li, X. Lei, Chem. 2019 5, 1671-1681; f) V. Singh, M. Porinchu, Tetrahedron 1996, 52, 20, 7087 7126; g) T. Uyehara, Y. Kabasawa, T. Kato, Bull. Chem. Soc. Jpn. 1986, 59, 2521-2518; h) D.-S. Hsu, Y.-Y. Chou, Y.-S. Tung, C.-C. Liao, Chem Eur. J. 2010, 16, 10, 3121-3131.

[5] S. Wilsey, M. J. Bearpark, F. Bernardi, M. Olivucci, M. A. Robb, J. Am. Chem. Soc. 1996, 118, 176-184.

[6] a) Y. Kawamoto, D. Ozone, T. Kobayashi, H. Ito, Org. Biomol. Chem. 2018, 16, 8477-8480; b) P. Magnus. D. Quagliato, J. Org. Chem. 1985 50, 1621-1626.

[7] F. Gallier, A. Martel, G. Dujardin, Angew. Chem. Int. Ed. 2017, 56, 41, 12424-12458; Angew. Chem. 2017, 129, 12598-12633.

[8] H. Shigehisa, T. Mizutani, S.-y. Tosaki, T. Ohshima, M. Shibasaki, Tetrahedron 2005, 61, 5057-5065.

[9] a) R. A. Moss, E. Y. Chen, J. Org. Chem. 1981, 46, 7, 1466-1469; b) V. Mutterer, E. Giminénez Arnau, A.-T. Karlberg, J.-P. Lepoittevin, Chem.
Res. Toxicol. 2000, 13, 10, 1028-1036; c) L. Cao, J. Sun, X. Wang, R. Zhu, H. Shi, Y. Hu, Tetrahedron 2007, 63, 23, 5036-5041.

[10] a) D. Belluš, D. R. Kearns, K. Schaffner, Helv. Chim. Acta 1969, 52, 4, 971-1009; b) S. L. Eng, R. Ricard, C. S. K. Wan, A. C. Weedon, J. Chem. Soc., Chem. Commun. 1983, 236-238; c) T. Bach, F. Höfer, J. Org. Chem. 2001, 66, 10, 3427-3434; d) R. Noyori, H. Inoue, M. Kato, Bull. Chem. Soc. Jpn. 1976, 49, 12, 3673-3678; e) N. Furutachi, J. Hayashi, H. Sato, K. Nakanishi, Tetrahedron Lett. 1972, 11, 1061-1064.

[11] a) N. Hoffmann, Chem. Rev. 2008, 108, 3, 1052-1103. b) P. S. Engel, M. A. Schexnayder, H. Ziffer, J. I. Seeman, J. Am. Chem. Soc. 1974, 96, 3 924-925.

[12] a) H. E. Zimmerman, G. L. Grunewald, J. Am. Chem. Soc. 1966, 88, 1, 183-184; b) H. E. Zimmerman, D. Armesto, Chem. Rev. 1996, 96,1, 3065-3112.

[13] E. Winterfeldt, Synthesis 1975, 9, 617-630.

[14] a) H.-J. Wang, Synthesis, 2009, 12, 2037-2038; b) K. Oesterreich, D. Spitzner, Tetrahedron 2002, 58, 4331-4334.

[15] S. Arseniyadis, D.V. Yashunsky, R. Perreira de Freitas, M. Muñoz Dorado, E. Toromanoff, P. Potier, Tetrahedron Lett. 1993, 34, 7, 1137 1140

[16] H. Hagiwara, H. Sakai, T. Uchiyama, Y. Ito, N. Morita, T. Hoshi, T. Suzuki, M. Ando, J. Chem. Soc., Perkin Trans. 1 2002, 583-591.

[17] S. Escher, W. Giersch, G. Ohloff, Helv. Chim. Acta 1981, 64, 4, 943-956.

[18] a) Z. G. Hajos, D. R. Parrish, Org. Synth. 1985, 63, 26; b) U. Eder, G. Sauer, R. Wiechert, Angew. Chem. 1971, 83, 13, 492-493; Angew. Chem. Int. Ed. 1971, 10, 7, 496-497.

[19] a) T. Gaich, P. S. Baran, J. Org. Chem. 2010, 75, 4657-4673; b) J. Schwan, M. Christmann, Chem. Soc. Rev. 2018, 47, 7985-7995. 